\title{
Feasibility study of bike sharing in Singapore
}

Jie Zhang, BEng

$\mathrm{PhD}$ candidate

School of Civil and Environmental Engineering, Nanyang Technological University, 50 Nanyang Avenue, Singapore 639798

Puay Ping Koh, BEng, MEng, PhD

Researcher

Centre for Infrastructure Systems, School of Civil and Environmental Engineering, Nanyang Technological University, 50 Nanyang Avenue, Singapore 639798

Meng Meng ${ }^{1,2}$, BEng, PhD

Research Fellow

1. Centre for Infrastructure Systems, School of Civil and Environmental Engineering, Nanyang Technological University, 50 Nanyang Avenue, Singapore 639798

2. TUM CREATE, 1 CREATE Way, 10-02 CREATE Tower, Singapore

Bok Wee Leow, BEng, MEng

Researcher

Centre for Infrastructure Systems, School of Civil and Environmental Engineering, Nanyang Technological University, 50 Nanyang Avenue, Singapore 639798

Yiik Diew Wong, BEng, PhD

Associate Professor

Centre for Infrastructure Systems, School of Civil and Environmental Engineering, Nanyang Technological University, 50 Nanyang Avenue, Singapore 639798

Corresponding author: Meng Meng, Email: mengm@ntu.edu.sg 


\section{Abstract}

This study analysed the feasibility of bike sharing programme in Singapore based on a case study in the Jurong Lake District. Data were collected using two-stage perception survey, first, to gather public's general awareness and opinion about bike sharing, and followed by estimating the likely take-up rate of bike sharing. Results showed that bike sharing schemes would be suitable around the mass rapid transit stations. Low rental cost would encourage bike sharing usage. Finally, a distance-based mode choice model was established for four scenarios (AM peak \& good weather, AM peak \& bad weather, PM peak \& good weather, PM peak \& bad weather) focusing on walking, bike sharing and taking bus. Weather could have an obvious impact on the frequency of bike sharing.

\section{Keywords}

Sustainability; Transport planning; Infrastructure planning; Bike sharing; Perception survey; Mode choice

\section{Introduction}

Bike sharing, as an alternate form of urban public transport, is getting respectably popular nowadays across the globe. It allows public commuters to share a pool of similarly configured bicycles operated out of convenient retrieve-and-return multi-stations. Its many benefits include promoting active transport, facilitating first/last mile trips to/from transit stations, improving access to amenities, offering a cheaper choice than public transport, and reducing the reliance on motorised transport (Meng et al., 2016). The pervasive spread of bike sharing schemes round the world suggests a prudent move to investigate the feasibility of bike sharing system locally in Singapore.

Singapore, an island city with $719 \mathrm{~km}^{2}$ land area and over 5.5 million inhabitants, has recognised the rising importance of bike sharing scheme. The Government agency has called for ideas on how to pilot a bike sharing programme in the city centre, regional town of Jurong Lake District and possibly residential towns like Tampines, Pasir Ris and Sembawang (Joy, 2014). By looking at other cities' experience, the first step of planning a bike sharing programme is to identify the potential area for the project, which has high consumer acceptance as well as take-up rate of bike sharing. Many cities in Europe, USA and Canada have conducted feasibility studies in recent years on bike sharing programmes (Transportation Canada, 2009; Transport for London, 2008; Department of City Planning, 2009). However, the experiences of the many 
bike sharing programmes in 4-season countries shall require careful study when applying relevant aspects to Singapore, where the tropical climate is hot and humid.

Singapore's Land Transport Authority (LTA) is placing impetus, amongst various cycling initiatives, to promote cycling usage through public bicycle rental scheme (Hoe, 2014). LTA announced in 2013 in the Land Transport Masterplan that a pilot bike sharing scheme shall be considered in the Jurong Lake District, As such, the present study is thus aimed at investigating the feasibility of bike sharing programme in Singapore which entailed conducting a two-stage survey in the Jurong Lake District to examine the potential level of acceptance and attendant usage of bike sharing. The research findings shall provide insights into the determinants of bike share rental in the Singapore's context.

\section{Literature review}

Bike sharing is known to start as early as 1965 in Amsterdam with the White Bikes. However, the programme collapsed within days as bikes were inappropriately used (e.g. thrown into canals or "converted" for private use) (DeMaio, 2009). Subsequently, the $2^{\text {nd }}$ generation bike sharing with improved modifications ranging from coin deposit to customer tracking appeared in the early 1990s. However, bicycle theft was still the major issue. The $3^{\text {rd }}$ generation bike sharing which utilised information and communication technology (ICT) (e.g. smartcard and automatic bike locks) started in mid 1990s but at a slow pace. It was not until the mid 2000s, when large scale $3^{\text {rd }}$ generation bike sharing became noticeable with the launch of Velo'v (France), Velib (Paris) and Bicing (Barcelona) (Ely and Brick, 2012). Besides Europe, countries such as China, New Zealand, Japan and US also started to launch bike sharing programmes in the 2000s. As of May 2017, the Bike-sharing World Map shows that a total of 1,286 cities operate bike share programmes with 3,415,750 bicycles in use (The Bike-sharing World Map, 2017).

The characteristics of bike sharing differ from city to city as it has to adapt to a city's attributes such as density of inhabitants, topography, weather, infrastructure availability and culture. As such, there is no single model of bike sharing. Nevertheless, common factors for raising bike sharing success rate can be identified in successful cases. These factors include: a dense 
network of bike sharing stations; comfortable bicycles with anti-theft functionality; easy, automated bike locking system; wireless tracking system, real-time monitoring system of occupancy, supporting information and communication technology platforms; and attractive pricing structure. By looking at the bike sharing schemes globally, some institutes have proposed several general guidebooks to support the planners' decision-making, e.g. The BikeShare Planning Guide (Institute for Transporatation and Development Policy, 2013) and Bike Share Station Siting Guide (National Association of City Transporatation Officials, 2016). Moreover, several cities also released their bicycle-sharing system planning guide according to the local conditions (Transporatation Canada, 2009; Optimising Bike Sharing in European Cities; 2011; Federal Highway Administration, 2012). These studies provide experiences for other cities in their pursuit for bike sharing.

As bike sharing is a fairly new transport scheme, stated preference survey which was developed in marketing studies in 1970s is well suited for investigating the travellers' acceptance and opinion on new public transport services.. In stated preference survey, respondents are invited to select their preferences among a set of choices/alternatives. This technique is widely used for transport service survey to understand the travellers' choice decision of certain service (Meng et al., 2016; Nguyen et al, 2015). The results shall contribute to the operator to well plan the project to attract more users.

\section{Methodology}

As shown in Figure 1, the study area encompasses three transit stations (Lakeside, Chinese Garden and Jurong East), two of which serve mainly neighbourhood residents and the other one serves a mixture of residents, shoppers and workers in the Jurong East township. The study area is about $11.4 \mathrm{~km}^{2}$, with a residential population of over 1 million.

The aim of the study is to gather information on the public's perception on bike sharing, using quota sampling instead of stratified random sampling. The reason is that currently there are not many cyclists as cycling as a principal transport mode accounts for only $1 \%$ of all trips in Singapore. One of the reasons for this low mode share is due to the lack of cycling infrastructure. The Government has released the National Cycling Plan to encourage the usage 
of cycling. There is a high likelihood that some passengers from rail transit stations will use bike sharing as their last mile mode to complete their trips in the future. Therefore, quota sampling method is used in this study to interview disembarking passengers from the rail transit stations.

A two-stage perception survey was administered from January 2014 to June 2014 . Stage 1 is to gather the public's general awareness and opinion about bike sharing and Stage 2 is to estimate the likely take-up rate of bike sharing.

The Stage 1 survey was conducted at the three transit stations, targeted to interview at least 150 transit commuters per station. Among which, at least 50 cyclists were to be interviewed per station randomly to represent one of the likely bike sharing uptake groups (i.e. change from use of personal to shared bicycles). The questions asked included whether the respondents know what bike sharing is, reasons to participate in a bike sharing programme and the form of bike sharing payment system.

For the Stage 2 survey, surveyors were deployed at "attractors", such as town centres and transit stations, during both peak and non-peak periods. Figure 3 shows the spread of the deployment areas (denoted by the circles) in the study location. Respondents were introduced to the "bike sharing" concept before answering the questions. Questions asked in this Stage 2 survey included how various conditions (weather, AM/PM peaks) affect respondent's decision to use bike sharing, their likely usage frequency and trip purpose, what bike sharing feature(s) would encourage its use and preferred service cost. A distance-based mode choice model could be developed based on the statistical results in this stage.

\section{Results and findings}

\subsection{Stage 1 - To gather public's awareness and option about bike sharing}

A total of 515 responses were gathered at the three transit stations. As cyclists were the intended "captives" (not a random sample) and local research has shown certain consistency of higher representation of male over female cyclists (Meng et al., 2016), it is not surprising that male respondents were over-represented in the sample (as compared to the usual 50:50 
national split). In terms of age groups, Jurong East had a higher proportion of respondents in the middle aged (employed) class compared to the other two transit stations. Two-thirds of the respondents were Singaporean, $6 \%$ were permanent residents while other nationalities took up about $28 \%$. A slightly higher proportion (72\%) of respondents in Jurong East was employed when compared to those in Lakeside and Chinese Garden (both at 61\%).

About one in four stated that they know what bike sharing is before the interviewers showed them the flashcard about bike sharing. The summary results are shown in Tables 1 and 2 . Among respondents who claimed that they know what bike sharing is, there were relatively higher proportions of them being cyclists in Lakeside and Chinese Garden (55\% vs $41 \%$ and $35 \%$ vs $27 \%$ ) than in Jurong East, being male (73\% vs $67 \%)$, and being from households owning bicycles (55\% vs $51 \%)$.

Table 1. Breakdown of total respondent demographics

\begin{tabular}{|c|c|c|c|c|}
\hline Location & Lakeside & $\begin{array}{l}\text { Chinese } \\
\text { Garden }\end{array}$ & Jurong East & Total \\
\hline Sample & 160 & 171 & 184 & 515 \\
\hline Cyclist & 65 (41\%) & 46 (27\%) & 45 (24\%) & 156 (30\%) \\
\hline Non-cyclist & 95 & 125 & 139 & 359 \\
\hline Male & 115 (72\%) & $103(60 \%)$ & $128(70 \%)$ & 346 (67\%) \\
\hline Female & 41 & 65 & 55 & 161 \\
\hline$<15$ & 6 & 5 & 1 & 12 \\
\hline $15-49$ & 125 (78\%) & 126 (74\%) & $168(91 \%)$ & 419 (81\%) \\
\hline $50-64$ & 22 & 25 & 12 & 59 \\
\hline$>64$ & 7 & 8 & 2 & 17 \\
\hline Employed & 97 (61\%) & 104 (61\%) & $133(72 \%)$ & 334 (65\%) \\
\hline Unemployed & 56 & 60 & 48 & 164 \\
\hline Own bicycle & 94 (59\%) & $82(48 \%)$ & $86(47 \%)$ & $262(51 \%)$ \\
\hline
\end{tabular}

Table 2. Breakdown of selected respondent demographics who were aware of bike sharing

\begin{tabular}{ccccc}
\hline Location & Lakeside & $\begin{array}{c}\text { Chinese } \\
\text { Garden }\end{array}$ & Jurong East & Total \\
\hline Sample & 33 & 54 & 45 & 132 \\
Cyclist & $18(\mathbf{5 5} \%)$ & $19(\mathbf{3 5 \%})$ & $9(20 \%)$ & $46(35 \%)$ \\
Non-cyclist & 15 & 35 & 36 & 86 \\
Male & $29(88 \%)$ & $34(63 \%)$ & $34(76 \%)$ & $97(\mathbf{7 3} \%)$ \\
Female & 4 & 20 & 11 & 35 \\
$<15$ & 0 & 1 & 0 & 1 \\
$15-49$ & $22(67 \%)$ & $41(76 \%)$ & $42(93 \%)$ & $105(80 \%)$ \\
$50-64$ & 9 & 9 & 3 & 21 \\
$>64$ & 2 & 3 & 0 & 5 \\
Employed & $25(76 \%)$ & $32(59 \%)$ & $31(69 \%)$ & $88(67 \%)$ \\
Unemployed & 8 & 22 & 14 & 40 \\
Own bicycle & $27(82 \%)$ & $28(52 \%)$ & $21(47 \%)$ & $73(55 \%)$ \\
\hline
\end{tabular}


Respondents were asked to select all the reasons listed in the question on why they might participate in bike sharing programme. About $24 \%$ would not participate in bike sharing at all. For those who are willing to participate in bike sharing, the top six reasons for them to participate were: bike sharing is a good idea; cycling as a form of exercise, convenience, and time saving; to support environmental causes; do not have to buy a bicycle; can save money; can cycle to/from massive rapid transit (MRT) station.

One in two respondents indicated that they were willing to pay for the bike sharing service if it is lower than the public transport rate, while $22 \%$ were willing to pay the same rate as public transport. One in four respondents was not willing to pay at all.

\subsection{Stage 2-To better estimate the likely take-up rate of bike sharing}

The overall male to female ratio is about 60:40. Middle-aged adults formed the largest group (with $76 \%$ ) and $41 \%$ of the respondents were employed. The respondents were asked to indicate how often they would likely use bike sharing services. The breakdown in Figure 2 shows that $9 \%$ of survey respondents would use such services on a daily basis, $26 \%$ for once or twice a week, $41 \%$ for occasional use while $23 \%$ were unsure.

The likely reasons or trip purposes for using bike sharing services were firstly for fitness (37\%), for varied purposes $(27 \%)$ such as running errands and shopping, followed by commuting to work/school (22\%). Respondents were asked to select the top three (out of 8 ) features that would encourage them to bike share. The top three features were low service cost, availability of bicycles at the transit stations/bus stops, and a convenient transaction system. When asked about the payment system of bike sharing, the majority (84\%) stated that they prefer pay-asyou-use rental fee, as compared to fixed monthly fee. For the fixed monthly fee, the average amount respondents were willing to pay is $\mathbf{S} \$ 29$ (with a range between $S \$ 2$ and $S \$ 100$ ) (1S\$ = $0.73 \cup S \$)$.

The respondents were also asked for a possible bike station location within the area where the survey was conducted. A majority suggested MRT stations, while others included community 
centres, residential areas, bus stops, schools and markets located in vicinity of survey sites. Other specific locations listed included the Jurong East Regional Library, the Singapore Science Centre, commercial shopping malls such as Jcube and Westgate, and residential shopping centres at Taman Jurong and Teban Place.

The respondents were presented with different scenarios (AM/PM peaks, good/poor weather) and were asked to choose their likely mode of transport from their homes to the nearest rail transit station. Table 3 shows the mode split ratio of the option chosen by the respondents. Under good weather conditions, about $30 \%$ will take bus, $53 \%$ would walk and $17 \%$ would choose bike sharing to the transit station. Under poor weather conditions (either raining or being very hot), $14 \%$ would walk and $2 \%$ would bike share. These mode shifts would result in substantial overloading of buses during poor weather ( $84 \%$ in AM peak and $82 \%$ in PM peak). Survey results showed little difference in terms of mode choice between AM and PM peaks for each weather scenario. The bike sharing proportion dropped sharply during poor weather compared to good weather.

However, the likelihood of choosing which mode is also highly distance dependent. For example, those living very close to the transit station would most likely choose to walk, rather than to bike share or take a bus; while those staying very far away would choose to take bus. Therefore, a distance-based mode choice model was established for each of the four scenarios.

Table 3. Mode split ratio chosen by the respondents

\begin{tabular}{ccccc}
\hline \multirow{2}{*}{ Mode } & \multicolumn{2}{c}{ AM peak } & \multicolumn{2}{c}{ PM peak } \\
\cline { 2 - 5 } & Good weather & Poor weather & Good weather & Poor weather \\
\hline Bus & $135(30 \%)$ & $385(84 \%)$ & $119(26 \%)$ & $375(82 \%)$ \\
Walk & $240(53 \%)$ & $62(14 \%)$ & $244(54 \%)$ & $72(16 \%)$ \\
Bike sharing & $79(17 \%)$ & $9(2 \%)$ & $93(20 \%)$ & $9(2 \%)$ \\
\hline
\end{tabular}

The dependent variable is the probability of selecting bike sharing, walking or taking bus and since it is a three-level categorical variable, logistic regression is suitable. The independent variable is the estimated distance to cycle between the respondent's home and nearest transit station, with the assumption that a cyclist would follow the footpaths alongside roadways. Four 
models were established for each scenario (AM peak \& good weather, AM peak \& poor weather, PM peak \& good weather, PM peak \& poor weather).

The Pearson Goodness-of-Fit statistics showed that all 4 models have significance probability (Pr) value of more than 0.05 ; there was insufficient evidence to reject the null hypothesis that the models fit the data. Table 4 summarises the distance-based mode choice models for each scenario (where bus is the reference category).

Table 4. Mode choice model for 4 scenarios

\begin{tabular}{|c|c|c|c|c|}
\hline $\begin{array}{c}\text { AMgood } \\
\text { Parameter }\end{array}$ & Mode & Estimate & Wald $x^{2}$ & $\operatorname{Pr}>x^{2}$ \\
\hline Intercept & Bike sharing & -0.93 & 3.30 & 0.0694 \\
\hline Intercept & Walk & 1.26 & 13.26 & 0.0003 \\
\hline Distance & Bike sharing & $-4.00 * 10^{-5}$ & 0.02 & 0.8958 \\
\hline Distance & Walk & $-5.50^{*} 10^{-4}$ & 5.85 & 0.0156 \\
\hline $\begin{array}{c}\text { AMpoor } \\
\text { Parameter }\end{array}$ & Mode & Estimate & Wald $x^{2}$ & $\operatorname{Pr}>x^{2}$ \\
\hline Intercept & Bike sharing & -2.43 & 1.80 & 0.1798 \\
\hline Intercept & Walk & -0.87 & 3.20 & 0.0738 \\
\hline Distance & Bike sharing & $-1.98^{*} 10^{-3}$ & 1.14 & 0.2861 \\
\hline Distance & Walk & $-8.50^{*} 10^{-4}$ & 4.71 & 0.0301 \\
\hline $\begin{array}{l}\text { PMgood } \\
\text { Parameter }\end{array}$ & Mode & Estimate & Wald $x^{2}$ & $\operatorname{Pr}>x^{2}$ \\
\hline Intercept & Bike sharing & 0.22 & 0.22 & 0.6456 \\
\hline Intercept & Walk & 1.78 & 22.52 & $<0.0001$ \\
\hline Distance & Bike sharing & $-4.80^{*} 10^{-4}$ & 2.57 & 0.1089 \\
\hline Distance & Walk & $-8.20^{*} 10^{-4}$ & 11.65 & 0.0006 \\
\hline $\begin{array}{c}\text { PMpoor } \\
\text { Parameter }\end{array}$ & Mode & Estimate & Wald $x^{2}$ & $\operatorname{Pr}>x^{2}$ \\
\hline Intercept & Bike sharing & -5.26 & 10.20 & 0.0014 \\
\hline Intercept & Walk & -0.85 & 3.39 & 0.0655 \\
\hline Distance & Bike sharing & $4.52^{*} 10^{-4}$ & 0.25 & 0.6206 \\
\hline Distance & Walk & $-7.70^{*} 10^{-4}$ & 4.41 & 0.0357 \\
\hline
\end{tabular}

During AM peak, the probability of choosing bike sharing would be almost maintained at about $27 \%$ regardless of the distance (as parameter for distance in this scenario is $-4.00^{*} 10^{-5}$ which is quite small to influence the final probability), whereas during PM peak, the odds of choosing to bike share decreases as distance increases. For example, every $100 \mathrm{~m}$ increase in distance for PM peak decreases the odds of bike sharing by $\mathrm{e}^{\left(-4.80^{*} 10-4^{*} 100\right)}=95 \%$. Taking $100 \mathrm{~m}$ as subsectioning interval, travel distance was divided into 29 segments. The distributive frequency and cumulative frequency of each segment for all 4 scenarios can be calculated as shown in Figure 3. Figure 3 shows that there would be few bike sharing trips if the travel distance were less than 
$700 \mathrm{~m}$ or longer than $2600 \mathrm{~m}$. The distance thresholds are decided from the survey data. Therefore, the probability of bike sharing for 4 scenarios (AM peak \& good weather, AM peak \& poor weather, PM peak \& good weather, PM peak \& poor weather) are given by the following equations:

$P(A M$, good $)=\frac{e^{-0.93-0.00004 \text { distance }}}{1+e^{-0.93-0.00004 \text { distance }}}, 700 m<$ distance $<2600 m$

1.

$P(A M$, poor $)=\frac{e^{-2.43-0.00198 \text { distance }}}{1+e^{-2.43-0.00198 \text { distance }}}, 700 m<$ distance $<2600 m$

2.

$P(P M$, good $)=\frac{e^{0.22-0.00048 \text { distance }}}{1+e^{0.22-0.00048 \text { distance }}}, 700 m<$ distance $<2600 m$

3.

$P(P M$, poor $)=\frac{e^{-5.26-0.000452 \text { distance }}}{1+e^{-5.26-0.000452 \text { distance }}}, 700 m<$ distance $<2600 m$

4.

Figure 4 depicts the probability of bike-sharing for all four different scenarios (AM peak and good weather, AM peak and poor weather, PM peak and good weather, PM peak and poor weather). In general, the propensity of choosing to bike share is very low during poor weather conditions.

\section{Conclusions}

A two-stage perception survey was conducted in the Jurong Lake District to investigate the feasibility of bike sharing in Singapore. Survey results showed that $25 \%$ of respondents already know what bike sharing is. Three in four (76\%) respondents had interests in participating in bike sharing. Pay-as-you-use payment form is more acceptable than fixed monthly fee, and half of the respondents were willing to pay for a bike-sharing service that charges a lower rate than that offered by public transport. Nearly one in five (17\%) respondents would bike share to the transit 
station under good weather condition, while most of them would switch to taking a bus if the weather were poor.

The top three features that would encourage respondents taking up bike sharing were low service cost, availability of bicycles at the transit stations/bus stops, and a convenient transaction system. Transit station is one of the most desired bike station locations, while other locations included community centres, residential areas, bus stops, schools and markets. In the event of bike sharing schemes going dock-less (as is now being introduced in Singapore), these high-activity locations should be well provided with adequate parking facilities in order to manage the 'parking problem' (Abdullah, 2017). Lastly, a distance-based mode choice model was established that offer new insights on the understanding of the influence of AM/PM peak and weather factors on the bike-sharing decision.

From the results, we could conclude that the future of bike sharing programme is promising. Bike sharing could be one of the best alternatives to solve the last mile connectivity issue from transit stations. Government could work closely with private companies to offer low service cost to users. The radius of service catchment area is suggested to be up to $2600 \mathrm{~m}$. Rebalancing issue should be considered during project planning especially for evening peak period due to the higher likelihood of selecting bike sharing during evening peak period. There will be fewer bike sharing users in adverse weather condition. For long term planning, cycling path with covered shelter will further promote the usage of bike sharing.

\section{References}

Abdullah Z (2017) Bikes from three firms going places as more people realise how convenient they are, although GPS can be a bit dodgy. Straits Times. Singapore. See: http://www.straitstimes.com/singapore/bike-sharing-users-share-perks-gripes

DeMaio P (2009) Bike-sharing: History, impacts, models of provision, and future. Journal of Public transportation 12(4):41-56.

Department of City Planning (2009) Bike-share opportunities in New York City. New York City. See: http://www.nyc.gov/html/dcp/pdf/transportation/bike_share_complete.pdf 
Ely M and Brick E (2012) Bicycle renaissance - in a shared way. Journeys, 9: 51-62.

Federal Highway Administration (2012) Bike sharing in the United States: state of the practice and guide to implementation. Washington DC, USA. See: http://www.bikesharing.ch/fileadmin/redaktion/bikesharing/Dokumente/Documents_et_autres /Bikesharing_in_the_United_States.pdf

Hoe PE (2014) LTA studying bike-sharing scheme to complement public transport system. The Straits Times. See: http://www.straitstimes.com/singapore/transport/lta-studying-bikesharing-scheme-to-complement-public-transport-system

Institute for Transportation and Development Policy (2013) The bike-sharing planning guide. New York, USA. See: https://go.itdp.org/display/live/The+Bike-Share+Planning+Guide

Joy F (2014) LTA ponders bike-sharing programme. Todayonline, 2014 July 3. See: http://www.todayonline.com/singapore/lta-ponders-bike-sharing-programme

Meng M, Koh PP and Wong YD (2016) Influence of socio-demography and operating streetscape on last-mile mode choice. Journal of Public Transportation 19(2): 38-54.

Meng M, Zhang J, Wong YD and Au PH (2016) Effect of Effect of weather conditions and weather forecast on cycling behaviour in Singapore. International Journal of Sustainable Transportation, 10(9): 773-780.

National Association of City Transportation Officials (2016) Bike share station siting guide. New York, USA. See: https://nacto.org/wp-content/uploads/2016/04/NACTO-Bike-Share-SitingGuide FINAL.pdf

Nguyen PN, Koh PP, and Wong YD (2015). Impacts of bicycle infrastructure: a case study in Singapore. Proceedings of the Institution of Civil Engineers - Municipal Engineer, 168(3): 186-198.

The Bike-sharing World Map (2017) World bike-sharing cities. See: www.bikesharingmap.com Transport for London (2008) Feasibility study for a central London cycle hire scheme. Transport for London. See: https://www.tfl.gov.uk/cdn/static/cms /documents/cycle-hire-schemefeasibility-full-report-nov2008.pdf

Transportation Canada (2009) Bike-sharing guide. Minister of Transport, Canada. See: www.fcm.ca/Documents/tools/GMF/Transport_Canada/BikeSharingGuide_EN.pdf 
Optimising Bike Sharing in European Cities (OBIS) (2011) Optimising bike sharing European cities - a handbook. OBIS. See: https://www.carplus.org.uk/wpcontent/uploads/2015/09/Obis-Handbook.pdf

\section{Figure captions}

Figure 1. Study area -Jurong Lake District (adapted from ArcGis map)

Figure 2. Breakdown on expected bike sharing usage

Figure 3. Frequency of choosing bike sharing with distance

Figure 4. Probability of choosing bike sharing for 4 scenarios 